\title{
ACERCA DE LAS NASALES DEL ESPAÑOL Y DEL GRIEGO. REFLEXIONES PARA LA ENSEÑANZA DEL ESPAÑOL A GRECOHABLANTES
}

\section{ABOUT SPANISH AND GREEK NASALS. REFLECTIONS FOR THE TEACHING OF SPANISH TO GREEK SPEAKERS}

\author{
Rosa M. ${ }^{a}$ Gómez García-Bermejo \\ Universidad de Valladolid, España \\ rosamaria.gomez.garcia-bermejo@uva.es \\ M. a Antonieta Andión Herrero \\ Universidad Nacional de Educación a Distancia, España \\ Grupo de investigación INVOLEX \\ maandion@flog.uned.es
}

Enviado: 03/09/2018

Aceptado: 17/07/2019

\section{Resumen}

La enseñanza del español en Grecia arrastra hoy las repercusiones negativas que la crisis económica ha tenido en el número de estudiantes de ELE del país heleno hasta finales de la primera década del siglo XXI. No obstante, el interés por el español continúa vivo. En el aprendizaje del español, los griegos encuentran una aparente facilidad fonética, que termina revelando dificultades por la falta de correspondencia fonológica entre las dos lenguas. Nos detenemos en este artículo en el estudio de la producción de los sonidos nasales del español por aprendices grecohablantes, a través de una comparación exhaustiva de estos sonidos y sus entornos vocálico y consonántico, así como de su condicionamiento dialectal y sociolingüístico

\begin{abstract}
The study of Spanish in Greece has been affected by the ramifications of the economic crisis, as the numbers of ELE students -a growth observed up until the end of the first decade of the 21st century - have started to plummet. Nevertheless, Spanish still manages to trigger enthusiasm and attract new learners. In particular, Greek-speaking learners benefit from the phonological system of their native language, which has significant affinities with the Spanish phonology and phonetics. This article analyses the production of nasals in Spanish by native Greek-speaking students, through the comparative examination thereof with their phonetic environment and their dialectic and sociolinguistic variation in Greek and Spanish. Subsequently,
\end{abstract}

Para citar este artículo / To cite this article: Gómez García-Bermejo, Rosa M. ${ }^{\mathrm{a}}$ y Andión Herrero, M. ${ }^{a}$ Antonieta (2019). Acerca de las nasales del español y del griego. Reflexiones para la enseñanza del español a grecohablantes. ELUA, 33: 89-110. doi: 10.14198/10.14198/ELUA2019.33.5

Enlace / Link: http://dx.doi.org/10.14198/ELUA2019.33.5 
en griego y en español. Reflexionamos sobre las posibles soluciones a errores fonéticos de estos estudiantes en relación con los sonidos nasales, que deben ser consideradas de acuerdo con el contexto y otras circunstancias de aprendizaje.

PALABRAS CLAVE: griego, español como lengua extranjera, nasales, enseñanza del español. we reflect on the possible strategies that could be followed in order to resolve the phonetic errors that stem from the nasality of the Spanish consonants, taking into account contextual factors, such as the teaching environment and process.

KEYWORDS: Greek, Spanish as a foreign language, nasal, teaching Spanish.

- ¿Qué consejo le darías a un docente de español que quisiera animarse a trabajar como profesor en Salónica? (Edinumen)

- ¿Consejos? No hay nada mejor como descubrir por uno mismo lo que nos rodea y puedo asegurar que Grecia no decepciona a casi nadie.

(Natividad Peramos)

\section{INTRODUCCIÓN}

En el siglo XXI el español sobrepasa los 480 millones de hablantes nativos, según las fuentes más autorizadas (Instituto Cervantes, 2018). Las cifras colocan al español entre las cinco lenguas con más hablantes del mundo si contamos los nativos, los de competencia limitada y los estudiantes de español, antecedida solo por el chino, lo que la convierte en una de las lenguas romances más extendidas (Andión y Casado 2014; López Morales 2012).

La masa poblacional hispana representa el 7,8 \% de la población mundial. Los cinco continentes cuentan con la presencia de hispanohablantes y muestran una impactante geografía que abarca el 9,1\% de la superficie terrestre emergida, más de doce millones de kilómetros cuadrados $^{1}$ : en Europa, España y Principado de Andorra; en América, Hispanoamérica y los Estados Unidos de Norteamérica (EE. UU.)²; en África, Guinea Ecuatorial, el Sahara Occidental y los territorios españoles de Islas Canarias, Ceuta y Melilla; en Asia, Filipinas e Israel y Turquía (sefardíes); y en Oceanía, la isla de Pascua. Debemos precisar que en algunos países antes mencionados el español no ha obtenido la oficialidad, aunque por razones históricas o migratorias existe una presencia importante de hispanohablantes: los ya mencionados EE. UU. (el $17 \%$ de su población es hispana, sin incluir la de Puerto Rico), Filipinas (el 3,53 $\%$ tiene el español como primera, segunda o tercera lengua), Brasil, Canadá, Marruecos... (Andión y Casado 2014; López Morales 2012; Moreno y Otero 2008).

Esta abultada demografía y la propia historia colonial expansiva de España hacen posible la mayoritaria convivencia del español con otras lenguas maternas en el mundo hispánico, reconocida oficialmente por países como en Bolivia, España, Guinea Ecuatorial, Paraguay,

1 Se pueden ampliar los datos en Moreno y Otero (2008).

2 Según palabras de López Morales (2012: 46), en 2050, los Estados Unidos serán para el primer país hispanohablante del mundo con 132 millones de hispanos. 
Perú, Puerto Rico, Sahara Occidental..., pero que no ha provocado la esperable pérdida de hablantes para la comunidad lingüística del español.

A pesar de su extensión y contacto con otras lenguas autóctonas, el español es hoy una lengua de indiscutible unidad (Andión y Casado 2014; López Morales 2012; Moreno y Otero 2008). Su estandarización monocéntrica, es decir, el carácter nuclear del modelo ortográfico, que viene apoyado por un copioso léxico también común y una gramática de importante cohesión morfosintáctica, permite al español el policentrismo de las normas cultas de sus diferentes comunidades de habla con modelos lingüísticos propios.

En su informe El español: una lengua viva, el Instituto Cervantes (2018) anota cifras muy interesantes sobre la presencia del español y sus hablantes en la red de redes: penetración de la lengua en la red del $63,3 \%^{3}$ y el 8,1\% de los internautas del mundo se comunica en español. En cuanto a las redes sociales, el español es la segunda lengua más utilizada en Facebook y Twitter, dejando atrás a otras como el portugués y el francés, y con posibilidades de convertirse en la primera lengua si sigue la incorporación de usuarios hispanos a estas plataformas de comunicación.

En este mismo documento se informa de que el español es el cuarto idioma más estudiado como lengua extranjera, por detrás del francés, del chino mandarín y del inglés (Instituto Cervantes 2018: 16). En Europa, el español es una de las cinco lenguas oficiales más utilizadas dentro de las instituciones comunitarias. El interés parece garantizado pues, según esta fuente, compartir el español "multiplica por cuatro las exportaciones bilaterales entre los países hispanohablantes" (Instituto Cervantes 2017: 30).

Todo lo anterior demuestra la fortaleza de un idioma que escala puestos internacionales relevantes y asegura su interés como lengua extranjera en muchos países. El gesto más llamativo hasta el momento ha sido el de Brasil con su conocida "Ley del Español" (Lei 11.161, de 05 de agosto de 2005), que obligó a las escuelas del Ensino médio brasileño a ofrecer el español como segunda lengua extranjera a sus alumnos y cuya aplicación ha sido disímil según estados. La Medida provisória n. ${ }^{\text { }}$ 746, de 22 de septiembre de 2016, con carácter general, introduce importantes modificaciones: en el currículo do Ensino fundamental, se ofrecerá la lengua inglesa a partir del sexto curso ( $6 .^{\circ}$ de Primaria) (art. 26) y los currículos de Ensino médio incluirán, obligatoriamente, el estudio de la lengua inglesa y podrán ofrecer otras lenguas extranjeras, con carácter optativo, de preferencia el español (art. 36), que en realidad, derogaba la "Ley del español". No obstante, ha habido -y hay- una gran movilización docente en defensa de nuestra lengua, que en casos como el del estado de Paraíba ha conseguido por ley equiparar el español al inglés en la oferta educativa (Lei 11.191, de 29 de agosto de 2018).

En esta prometedora situación global, cada país presenta un panorama propio condicionado por las circunstancias de su relación pasada y presente con la lengua española y de sus expectativas actuales. En el caso de Grecia, de especial interés para este trabajo, su relación con el español no ha sido muy estrecha a pesar de contar con una presencia sefardita antigua. Según Péramos Soler, "con la 2. ${ }^{a}$ Guerra Mundial la población de judíos descendió de 56000 habitantes en 1940 a menos de 1300 en 1959” (Peramos Soler 2008). Tras las consecuencias del holocausto nazi, la hasta entonces próspera vida sefardí no se recuperó (VV. AA. 2009).

3 La penetración de una lengua en Internet expresa la relación entre el número de usuarios en la red de esa lengua y el número global de la población del idioma en el mundo. 
La situación geográfica de Grecia — que limita por el norte con los países balcánicos, y que siempre ha tenido un acercamiento, comercialmente hablando, muy estrecho con Italia - no ha favorecido el contacto con España a la que siempre se ha visto como un destino turístico. Es por esto por lo que el español se aprende por interés personal y no por una necesidad laboral. A pesar de esto, son numerosos los griegos que estudian español. Asimismo, nuestra cultura, muy similar a la griega, se siente como muy próxima.

La enorme crisis económica sufrida por este país en los últimos años, que ha afectado a sectores tanto públicos como privados, ha provocado una disminución del número de alumnos, pero no del interés ni la inclinación por cultura e idioma españoles.

Para los hablantes de griego, uno de los atractivos del español es precisamente la fonética pues las dificultades de pronunciación a las que se enfrentan son escasas y los sonidos -también los vocablos nuevos- son reconocibles desde los primeros momentos del aprendizaje. A ello contribuye el hecho de que los sistemas vocálicos sean exactamente iguales. En cuanto a las consonantes, el número es parecido (19 en español y 20 en griego); no obstante, existen algunas diferencias, pero son fácilmente superables (Hernández de la Fuente 2001). Sin embargo, la percepción de la dificultad entre estas dos lenguas, cuando no se trata de la L1 sino de lenguas extranjeras ${ }^{4}$, es diferente para sus aprendices. En la práctica, un hispanohablante - concretamente, un español - tendría más dificultades para adquirir la lengua griega y llegar a una pronunciación correcta, pues los grecófonos se esmeran en pronunciar tanto las vocales como las consonantes o grupos de consonantes, ya que la supresión de alguna de ellas - hecho frecuente en el habla relajada del hispanófono- sufre estigmas sociales (Garavelas 2012).

En este artículo nos centraremos en el aprendizaje de ELE desde la perspectiva de un estudiante grecohablante y, específicamente, en lo que afecta a las nasales y palatales. Nos ceñiremos a la variedad estándar de la lengua griega, por ser esta la más extendida y la que goza de mayor prestigio social ${ }^{5}$.

Empezaremos por reconocer y contrastar el paradigma fonológico del español y del griego, en especial el nasal y el palatal con él relacionado, deteniéndonos en sus variantes alofónicas, propias de las adaptaciones a la fonotaxis ${ }^{6}$ de cada lengua, y geolectales. Este acercamiento contrastivo permitirá describir el comportamiento de los sonidos de carácter nasal en ambas lenguas teniendo en cuenta las características que los provocan y las interferencias ${ }^{7}$ que estos hablantes presentan en español. En atención a estas particularidades y su previsible influencia en la interlengua de los aprendices griegos de ELE, que apoyamos

4 Somos conscientes de la distinción entre lengua 'segunda' $\left(\mathrm{L}_{2}\right)$ y lengua 'extranjera' (LE) desde el punto de vista sociolingüístico: la 'segunda lengua' es la que se enseña en un entorno donde es medio de comunicación, y la 'extranjera', donde no lo es (Richards, Platt y Platt 1997); o en términos usados por Moreno (2010), el español$\mathrm{L}_{2}$ sería enseñado en un entorno homosiglósico y el español-LE, en uno heterosiglósico. No obstante, usaremos extranjera por no ser rentable su distinción en el presente trabajo.

5 Para ampliar esta información recomendamos consultar a María Kakride-Ferrari (2007) y Marina Mattheoudakis (2014).

6 Entendemos la fonotaxis en el sentido aplicado por Quilis (1999: 149) de "el orden de los sonidos", es decir, las posibilidades combinatorias de estos.

7 Utilizamos interferencia para referirnos a los errores de un aprendiz en la lengua extranjera causados por los conocimientos — lingüísticos o de otro tipo — previos y transferidos desde su lengua materna. Vale la pena aclarar que no consideramos, como en el análisis contrastivo de los primeros momentos (Fries 1945; Lado 1957; Weinreich 1953), que todos los errores de la interlengua de un aprendiz se expliquen por las transferencias negativas de su lengua materna (Fernández 1997; Santos Gargallo 1993). 
también con la observación basada en nuestra experiencia docente, aportaremos consideraciones de interés para la enseñanza de nasales y palatales del español a estos estudiantes. Esperamos que estas reflexiones y llamadas de atención sobre las realizaciones de estos sonidos, cuyas dificultades terminan fosilizando y mermando la competencia fonética de los aprendices helenos, sean útiles para sus profesores.

\section{LA ENSEÑANZA DEL ESPAÑOL EN GRECIA}

A pesar del enorme interés que despierta en los griegos tanto el idioma español como la cultura hispánica, su enseñanza en Grecia ha sufrido muchos altibajos, a decir verdad, más bajos que altos. Podemos decir que su historia más cierta comienza en 1976, cuando Juan Nadal Cañellas, agregado cultural de la Embajada de España, funda y dirige el Instituto Cultural Español "Reina Sofía", que pasará a ser el Instituto Cervantes de Atenas en 1992. Hasta ese momento, quienes querían aprender español debían hacerlo en clases particulares o en alguna de las escasas academias privadas de las grandes capitales griegas. En aquella época, el acercamiento a la lengua española era minoritario y elitista (Rodríguez-Lifante 2015). Casi todos los alumnos que se sentían atraídos por ella ya sabían dos o tres idiomas extranjeros, eran personas cultas y con inquietudes personales. No dejaba de resultar extraño o exótico que alguien estudiara español.

Tras la entrada de España en la Unión Europea en 1986, que marca la salida del aislamiento internacional y el comienzo del despegue económico del país ibérico, Grecia empieza a manifestar un interés ascendente por la lengua de Cervantes. Sin embargo, mientras que en Europa las personas que estudian español lo hacen dentro de la enseñanza reglada [92,6 \% en 2001, según Luján (2002)]; en Grecia, el sector privado, en exclusividad, recoge el creciente número de alumnos que desean aprenderlo en esta última década del siglo XX. En 1999, comienza a impartirse Español en la Universidad Nacional y Kapodistríaca de Atenas, donde al finalizar los estudios se obtenía el título de Filología Italiana e Hispánica. Nueve años después, en 2008, se independiza el título como Filología Hispánica. Por otro lado, en la Universidad Abierta (universidad a distancia de Grecia), existe un departamento de Lengua Española y Cultura desde 2002. Asimismo, en 2001, en la Universidad Jónica de Corfú, se creó el título de Especialización en Lengua y Cultura Españolas y su Didáctica como Lengua Extranjera, dentro del programa de estudios de Traducción e Interpretación. A nivel universitario, el interés institucional por el español era evidente.

Todos los alumnos que accedían a las titulaciones mencionadas, habían adquirido sus conocimientos de español en centros privados (o relacionados con la administración educativa española, como el Instituto Cervantes), puesto que la introducción del español en la enseñanza reglada no universitaria fue muy tardía. En el curso 2006-2007, se aplicó un programa piloto en seis centros de secundaria con 120 alumnos. El curso siguiente estos se duplicaron a 268 y el tercer año llegaron a 534 en un total de 11 centros (Leontaridi 2009: 201).

A pesar de que hasta el 2006 la enseñanza reglada del español no aparece ni en primaria ni en secundaria, hay varios datos que demuestran el enorme empuje que tuvo el español en estos primeros años del siglo XXI. En primer lugar, el llamativo incremento de centros privados que ofrecían ELE y del número de alumnos que acogían; según Rodríguez Lifante (2010: 17), de los 80 centros que existían en el 2000 y en los que 3500 personas aproximadamente estudiaban español, se pasó en 2007 a 373 academias con 20000 alumnos. Es 
de suponer que en estas escuelas privadas, llamadas en Grecia frontistiria ( $\varphi \rho \circ v \tau \imath \sigma \tau \eta ́ p ı \alpha)$, el número fuera aún mayor al no estar registradas todas las que incluyeron el español por petición de los alumnos.

En segundo lugar, este aumento se ve reflejado en los datos del Didaskaleio $(\Delta t \delta \alpha \sigma \kappa \alpha \lambda \varepsilon$ cío $\Xi \varepsilon ́ v \omega v \Gamma \lambda \omega \sigma \sigma \omega ́ v)$, centro dependiente de la universidad Kapodistríaca de Atenas, en el que se imparten clases de idiomas extranjeros, destinadas en su mayor parte a estudiantes universitarios. En el curso 2005-2006, llegaron a tener 888 estudiantes de español, superando en número de alumnos al resto de los idiomas impartidos [incluidos el inglés, francés y alemán (Leontaridi 2009: 205)].

Quizás el dato más sorprendente que evidencia el auge del español en Grecia, cuya población es tan solo de unos once millones de habitantes, está en que tuviera el mayor número de participantes del mundo por país en los Diplomas de Español Lengua Extranjera (DELE) de 2005. Con sus 6653 examinados superó incluso a Brasil. En los años siguientes, llegó a alcanzar los $6894(2008)^{8}$.

A finales de esta primera década del siglo, las expectativas del español en Grecia eran muy halagüeñas. En julio de 2009, en una entrevista a Eusebi Ayensa Prat, el entonces director del Instituto Cervantes de Atenas afirma que "el español tiene muchas posibilidades de convertirse en una lengua potente en Grecia [...] Creo firmemente que en la enseñanza reglada puede convertirse en una lengua muy importante, a pesar de las reacciones que puede haber [...] de asociaciones de profesores de francés o de otros idiomas contra el español" (Kouti, 2009). La respuesta de Ayensa, además, sugiere la creciente -para otros, amenazante- simpatía que despertaba el español en los estudiantes griegos. En este sentido, la encuesta realizada por Castellanos (2006) en el Instituto Cervantes de Atenas demuestra que el motivo fundamental para estudiar español en los alumnos es la satisfacción personal, muy superior a las razones profesionales o culturales 9 .

Este panorama tan favorecedor se vería truncado por la desgarradora crisis económica que sufrió toda Europa, pero especialmente Grecia. Sus nefastas consecuencias afectaron a todos los sectores económicos, políticos y culturales del país, también —obviamente- a la educación y a la enseñanza de idiomas extranjeros, entre ellos, el español. A partir de 2008, el número de candidatos a los DELE empezó a descender paulatinamente, aunque también tenemos que considerar el hecho de que el Estado griego implantó en esos años los Exámenes

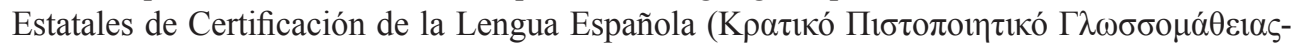
КПГ) con validez dentro del territorio nacional. No obstante, esta "competencia" de diplomas no sería decisiva si tenemos en cuenta dos factores: el hecho de que, en un primer momento, los exámenes estatales solo tenían el B2; y en segundo lugar, que los candidatos, en general, preferían presentarse a los DELE, pues gozaban de más reconocimiento y prestigio. Por ello, nos inclinamos a pensar que el descenso en las matrículas es una secuela de la fuerte crisis económica, ya en ciernes en todos los sectores de la sociedad griega.

Lo cierto es que los índices de afluencia de estudiantes de ELE comienzan a descender sensible y consecutivamente a partir de 2006 también en la enseñanza privada: se resiente el número de centros que imparten español, incluyendo el Didaskaleio de la universidad de

8 Para una información más detallada al respecto, pueden consultarse los trabajos realizados por Leontaridi (2009) y Rodríguez-Lifante (2015).

9 Castellanos (2006) también incluye en su estudio otros centros Cervantes, a saber, de Alejandría, Ammán, Argel, Beirut, Burdeos, Damasco, Dublín, El Cairo, Lisboa, Londres, Manila, Milán, Nápoles, Oporto, París, entre otros. 
Atenas, etc. En cuanto a la enseñanza reglada, al coincidir su implantación en secundaria con la crisis y con los recortes presupuestarios, según palabras de Ana M. ${ }^{a}$ Rodríguez Gil, Asesora Técnica Docente de la Consejería de Educación de Italia, Grecia y Albania, en estos momentos, en Grecia no queda rastro alguno ${ }^{10}$.

Aunque en 2011 ya había varios centros que impartían español, esparcidos en distintos puntos de la geografía griega (Atenas y región del Ática, Salónica, creta, Larissa, Patras y Tripoli), la situación económica del país (Papamatthaiou 2011) hizo que el gobierno griego emitiera una decisión ministerial el 2 de junio de 2011 por la que, en las escuelas públicas, desaparecerían tanto el español lengua extranjera (ELE) como el italiano. En cuanto a las universidades, la de Atenas continúa hoy su labor, la de Corfú dejó de ofrecer el grado de Especialización en Lengua y Cultura Españolas y la Universidad Abierta sigue formando a estudiantes en Lengua Española y Cultura ${ }^{11}$. No podemos menos que estar de acuerdo con Chatzes (2017) en que "continúa existiendo una gran demanda", el interés por el español permanece y nos aventuramos a pensar que quedará en espera de circunstancias más propicias.

\section{EL SISTEMA FONOLÓGICO GRIEGO: BREVE DESCRIPCIÓN DE SUS RAS- GOS GENERALES}

Para entender mejor las diferencias fónicas entre el griego y el español resulta útil partir de la realidad fonológica del español y explicar comparativamente los rasgos generales del sistema griego. De este modo se pondrán de relieve con más claridad los puntos "conflictivos".

Abordaremos la explicación tomando como punto de partida las pautas marcadas por Martinet (1968) y las del volumen de Fonética y Fonología de la Nueva gramática de la lengua española (NGLE) (RAE y ASALE 2011). Por ello, separamos los elementos distintivos de cada fonema mediante conmutación, es decir, confrontamos un fonema ${ }^{12}$ con otros próximos a él, o lo que es lo mismo, con otros que tengan varias propiedades comunes, y vemos sus diferencias y oposiciones. En segundo lugar, analizamos las variantes de cada fonema, tanto las que dependen del entorno en el que se encuentra (variantes combinatorias), como las que dependen del idiolecto o circunstancias del hablante (variantes libres) ${ }^{13}$. Puesto que trabajamos con dos sistemas fonológicos distintos, cuando se trate del hablante griego, la transcripción se adecuará a su sistema fonológico; por el contrario, si nos referimos al español, los fonemas que aparezcan responderán a nuestra lengua. Por otro lado, hemos preferido poner la tilde sobre la vocal acentuada -y no delante de la sílaba a la que pertenece, como se hace en el Sistema Alfabético Internacional (AFI) - para facilitar la lectura de los ejemplos tanto en griego como en español.

La primera división que proponemos para tratar las diferencias fónicas relevantes es la de consonantes y vocales. Las primeras se producen mediante una constricción o estrechamiento en el tracto vocal, mientras que las segundas no presentan obstáculos a la salida del aire (NGLE 2011: 5).

10 Comunicación personal de la Sr. ${ }^{a}$ Rodríguez Gil a través de correo electrónico de 4 de agosto de 2017.

11 Aunque parezca injustificado, desde 2013 el Estado no permite que los graduados de la Universidad Abierta ejerzan como profesores de ELE (Chatzes, 2017).

12 Entendemos por fonema una unidad abstracta que incluye distintas realizaciones, siempre que integren unos rasgos distintivos característicos (RAE y ASALE 2011: 5).

13 Seguiremos las pautas de la lingüística actual y damos la transcripción fonológica entre barras /.../, mientras que la transcripción fonética aparece entre corchetes [...]. 


\subsection{Fonemas vocálicos}

Como ya anunciamos, no existen diferencias entre los sistemas vocálicos del español y del griego (Hernández de la Fuente 2001). Son características de ambos su claridad y simplicidad. Nos encontramos frente a sistemas triangulares en los que solo se debe tener en cuenta el grado de abertura y la configuración de la cavidad bucal según la posición de la lengua y los labios. No obstante, existen diferencias de pronunciación en las vocales griegas con arreglo al lugar que ocupa el sonido en la cadena hablada o al idiolecto del hablante. Entre los sonidos vocálicos griegos -y dialectales del español- encontramos variantes largas, breves, abiertas, cerradas, nasales, orales, etc. que concretan, obviamente, los estándares de descripción fonológica. Tanto el aprendiz griego como el hispanohablante no suelen tener conciencia de dichas variantes, constituyen diferencias fonéticas y no fonológicas, no diferencian significados y no son distintivas.

Encontramos así tres grados de abertura vocálica en griego y español:

Máxima: /a/

Media: /e, o/

Mínima: /i, u/

Y con respecto a la configuración de la cavidad bucal, tenemos vocales:

Posteriores: /u, o/

Media: /a/

Anteriores: /e, i/

Existen, por tanto, en ambos sistemas, cinco fonemas vocálicos que se definen del siguiente modo:

/a/ Fonema vocal de abertura máxima, de localización media.

/e/ Fonema vocal de abertura media, de localización anterior.

/i/ Fonema vocal de abertura mínima, de localización anterior.

/o/ Fonema vocal de abertura media, de localización posterior.

/u/ Fonema vocal de abertura mínima, de localización posterior.

$\mathrm{Su}$ valor diferencial se demuestra mediante oposiciones de palabras; tanto en un idioma como en el otro, podemos apreciar que la conmutación de cada una de las cinco vocales es suficiente para cambiar el significado de la palabra.

Entendemos los sonidos que integran los diptongos como variantes combinatorias de los fonemas $/ \mathrm{a} /, / \mathrm{e} /, / \mathrm{i} /, / \mathrm{o} /, / \mathrm{u} /{ }^{14}$, en las que las semivocales y semiconsonantes son resultado de su producción en condiciones especiales cuando no forman parte del núcleo silábico ${ }^{15}$. Por lo mismo, los triptongos, combinaciones de tres fonemas distintos dentro de una misma sílaba, son infrecuentes en ambos idiomas. Al ponerse en contacto, en el discurso, dos fonemas vocálicos son casi siempre pronunciados en sílabas diferentes, a excepción de que una de las vocales sea "i" o "u" átonas. En dicho caso, las mismas actuarían como vocales de paso $^{16}$. Sin embargo, en ambos idiomas, un grupo vocálico que contenga una vocal débil

14 Según Trubetzkoy (1949), una combinación de sonidos potencialmente monofonemática solo debe valorarse como fonema único cuando uno de aquellos sonidos no pueda considerarse variante combinatoria de ningún otro fonema.

15 Consideramos que los diptongos no tienen valor monofonemático sino difonemático (Trubetzkoy 1949); es decir, son combinaciones de los cinco fonemas vocálicos expuestos.

16 Bien sean estas semiconsonantes o semivocales. 
no siempre se articula como diptongo (Kouti 2006). De este modo, en palabras derivadas de otras que sí tenían acentuada la vocal débil, es habitual pronunciarlas en hiato; por ejemplo,

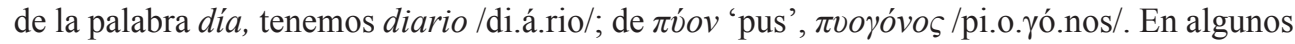
vocablos se prefiere la pronunciación en hiato, como en santuario /san.tu.á.rio/ o en $\varphi \imath \alpha ́ \lambda \eta$ /fi.á.li/. Ello no impide que escuchemos también la variante diptongada, aunque en menos ocasiones. Sin embargo, algunas combinaciones se pronuncian con hiato o no indistintamen-

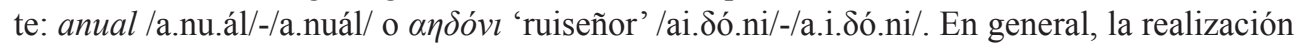
de la secuencia vocálica como diptongo o hiato pasa inadvertida al hablante, depende en gran medida de la rapidez o relajación del habla. Consideramos una excepción a lo anterior el caso de los diptongos crecientes en griego. Estos incluyen un refuerzo consonántico que los diferencia del resto. Refuerzo que puede ser palatal fricativo sordo [ç], como en $\pi$ colo

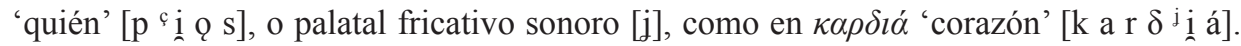

También, en los dos idiomas, es posible que dos vocales de abertura máxima o media formen diptongo al pronunciar una de ellas de forma más cerrada y breve.

Resumiendo, tanto en español como en griego, son solo cinco los fonemas vocálicos, que coinciden en su modo y punto de articulación (Hernández de la Fuente 2001). La posible transferencia facilita enormemente la percepción de lo expresado, además de hacer sencilla la producción. No obstante, en ambos idiomas, las vocales son importantes; sobre todo en español, lengua en la que la debilidad y elisión consonántica es algo habitual en determinados contornos y variantes, tanto dialectales como diafásicas o diastráticas. Sin embargo, en nuestra lengua, la supresión o mala articulación de una vocal nuclear podría tener como resultado, en la mayoría de los casos, una situación de incomprensión ${ }^{17}$. Pensemos en lo arduo que resulta entender a un aprendiz anglófono de niveles bajos cuando deforma o reduce las vocales del español, o en la pronunciación de un portugués (no tanto de un brasileño) en la que apenas se aprecian las vocales.

\subsection{Fonemas consonánticos}

Al comparar las consonantes del griego y las del español, debemos empezar por distinguir, según el modo de articulación, entre los fonemas orales, en los que el aire sale -con mayor o menor dificultad - por la boca, los nasales, que se realizan con ayuda del resonador de las fosas nasales, y los líquidos, en los que el contacto de la lengua con la zona central hace que el aire pase por los laterales. En los primeros (fonemas orales) realizaremos una división inicial atendiendo a la sonoridad (vibración o no de las cuerdas vocales), a fin de ver más claramente las diferencias y semejanzas fonológicas entre los dos idiomas. De este modo, obtenemos dos series: una de fonemas sonoros - con vibración glotal- y otra de fonemas sordos. A su vez, estas series aparecen divididas según su pronunciación oclusiva, en la que momentáneamente aparece un cierre total a la salida del aire, o fricativa, con un estrechamiento debido a la aproximación de los órganos articulatorios que no interrumpe por completo la salida del aire (Tabla 1).

17 No siempre ocurre esta incomprensión, ya que existen variedades del español en las que se produce debilitamiento y pérdida de vocales átonas (an[ts] antes, ca[fs]ito cafecito), rasgo propio de México (meseta) y Centroamérica (El Salvador), los Andes (Bolivia, Colombia, Ecuador, Perú) y el Río de la Plata (Santiago del Estero en Argentina) (Andión y Casado 2014). 


\begin{tabular}{|l|l|l|l|l|l|l|}
\hline \multicolumn{3}{|c|}{ ESPAÑOL } & \multicolumn{4}{c|}{ GRIEGO } \\
\hline \multirow{2}{*}{ Sonoros } & \multicolumn{2}{|c|}{ Sordos } & \multicolumn{2}{c|}{ Sonoros } & \multicolumn{2}{c|}{ Sordos } \\
\cline { 2 - 7 } & Oclusivos & Fricativos & Oclusivos & Fricativos & Oclusivos & Fricativos \\
\hline $\begin{array}{l}/ \mathrm{b} /, / \mathrm{d} /, / \mathrm{j} /, \\
/ \mathrm{g} /\end{array}$ & $\begin{array}{l}/ \mathrm{p} /, / \mathrm{t} /, / \mathrm{t \textrm {t }} /, \\
/ \mathrm{k} /\end{array}$ & $\begin{array}{l}/ \mathrm{f} /, / \theta /, / \mathrm{s} /, \\
/ \mathrm{x} /\end{array}$ & $\begin{array}{l}/ \mathrm{b} /, / \mathrm{d} / / /[\mathrm{d}] /, \\
/ \mathrm{g} /\end{array}$ & $\begin{array}{l}/ \beta /, / \delta /, / \mathrm{z} /, \\
/ \gamma /\end{array}$ & $\begin{array}{l}/ \mathrm{p} /, / \mathrm{t} /, / \mathrm{t} \mathrm{f} /, \\
/ \mathrm{k} /\end{array}$ & $\begin{array}{l}/ \mathrm{f} /, / \theta /, / \mathrm{s} /, \\
/ \mathrm{x} /\end{array}$ \\
\hline
\end{tabular}

Tabla 1. Fonemas consonánticos del español y del griego

Si miramos con detenimiento la tabla anterior, observamos que los fonemas sordos de ambos sistemas coinciden; en ellos la correlación de continuidad (realización oclusiva o fricativa) es distintiva. Esta característica permite diferenciar los pares sordos en español:

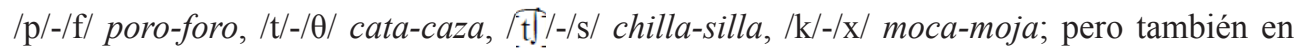

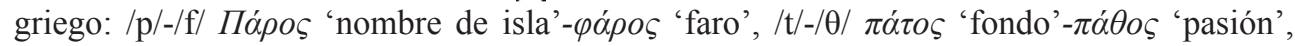

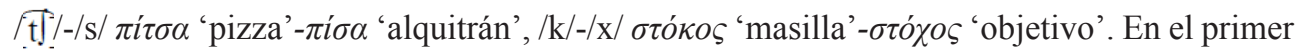
fonema de cada par la realización es interrupta y en el segundo, continua.

Sin embargo, en la correlación de sonoridad, el rasgo de plosión-fricción no es distintivo en español -pero sí en griego- y no permite diferenciar significados. La oposición de [b] interrupta y $[\beta]$ continua depende exclusivamente del contorno en que aparezca. Así, por ejemplo, en español, la transcripción fonética de la palabra bien podría ser tanto [bién] como

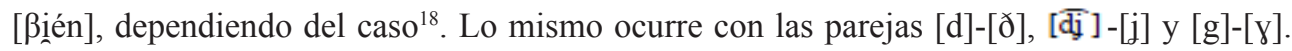
No son más que variantes combinatorias o libres de los fonemas únicos $/ \mathrm{d} /, / \mathrm{j} /, / \mathrm{g} /$. En su mayoría, la realización de una u otra depende del entorno, aunque a veces, como en el caso de [ד]j]-[j], la diferencia puede ser también consecuencia de una pronunciación enfática o dialectal. Obtenemos así haces de tres términos en español (Figura 1).
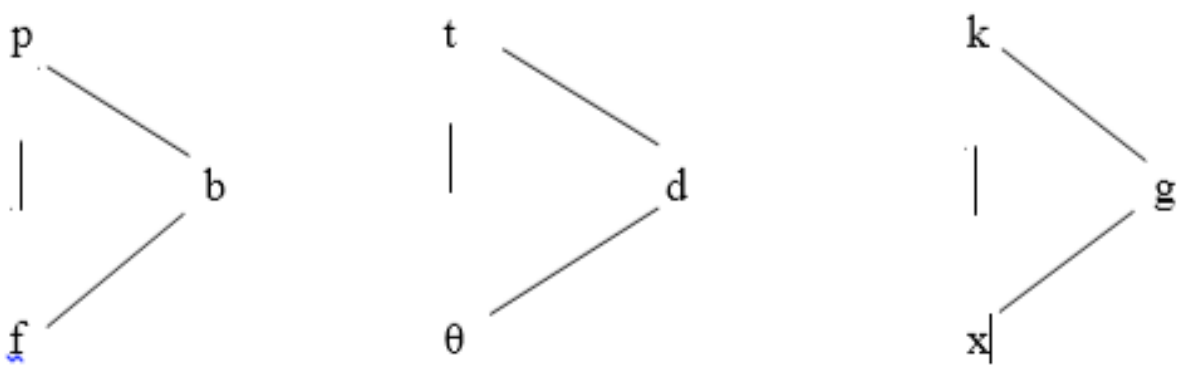

Figura 1. Haces de fonemas oclusivos y fricativos en español

\footnotetext{
18 También existen dos letras que representan el fonema /b/ en español: $b$ y $v$. Su articulación depende del contexto en que se encuentren y no de su grafía: en la palabra envío se articula un sonido oclusivo, mientras que en cava o cabo es fricativo.
} 
Sin embargo, en griego, la cualidad de la sonoridad no es válida por sí sola; dentro de los fonemas sonoros debemos distinguir entre oclusivos y fricativos, al igual que en los sordos. Para el griego, los haces formados por las correlaciones de sonoridad y continuidad son de cuatro términos (Figura 2).
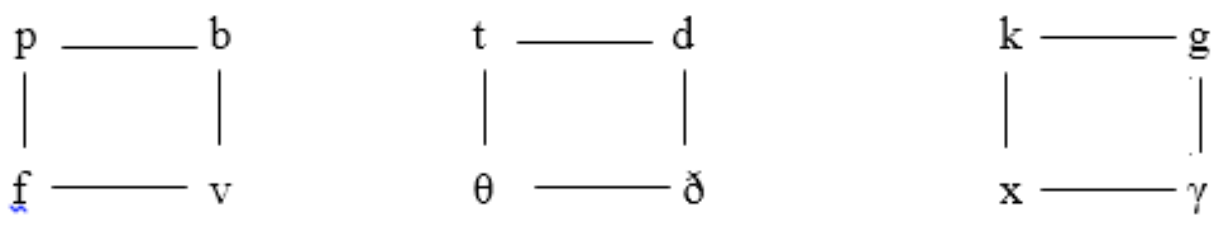

Figura 2. Haces de fonemas oclusivos y fricativos en griego

Puesto que en este idioma existe tal distinción fonológica, cabría esperar que los aprendices griegos reconocieran los alófonos fricativos y oclusivos del español, puesto que son fonemas diferenciados para los grecohablantes. Sin embargo, nuestra experiencia es que esto no ocurre así. En primer lugar, porque el input que reciben estos estudiantes de ELE es, simultáneamente, escrito y oral, y un griego pronuncia como oclusivas las grafías $b, d$, $g$, al igual que lo hace en otros idiomas presentes en su contexto educativo, como pueden ser el inglés, el francés o el italiano. En segundo lugar, al percibir las variantes fricativas no las relacionan con sus fonemas ya que, en realidad, la articulación en español no es fricativa sino aproximante. Este pequeño matiz de un cierre u obstaculización menor a la salida del aire contribuye a que no identifique nuestros alófonos fricativos, aproximantes, con sus fonemas fricativos.

Ahora bien, la diferencia entre los sonidos [đj] y [j] es más fácil de percibir porque, en griego, [dj] es un fonema $/ \mathrm{dj} /$, bien diferenciado del sonido [j], que es un alófono del fonema $/ \mathrm{y} /$ ante las vocales anteriores $e, i$. Frecuentemente los alumnos preguntan si la pro-

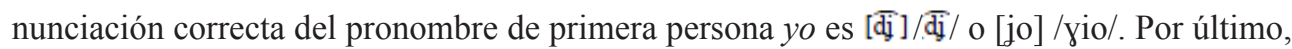

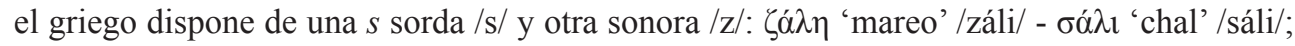
dos vocablos diferenciados fonéticamente: ambos fricativos alveolares, pero uno sordo y otro sonoro.

En cuanto a los fonemas líquidos - sonoros todos- del español, existen dos laterales y dos vibrantes, no considerando, por supuesto, la variante yeísta ${ }^{19}$. El cuadro fonológico queda, entonces, como sigue:

- Laterales $/ 1 /, / K /$

- Vibrantes / / /, / r/

Por el contrario, en griego, solo encontramos un fonema en cada lugar de articulación:

- Laterales /1/

- Vibrantes // /

19 La distinción $[K]$-[j] tiene un territorio cada vez menos extenso en español. En España distingue la parte norte de las Castillas, y en Hispanoamérica, parte de los Andes (oeste de Bolivia, sierra de Ecuador y Perú), del Río de la Plata (norte de Argentina, Paraguay, parte de Argentina con influjo guaraní) y de Chile (sur de Santiago). El resto, más extenso y sobre todo urbano, prefiere la articulación yeísta (neutralización de ambos sonidos en [j]) (Andión y Casado 2014). 
No obstante, este idioma dispone de los sonidos $[K]$ y $[\mathrm{r}]$, alófonos de /1/ y /r/. El fonema /1/ sufre una palatalización $[K]$ seguido de la semiconsonante [i] (es decir, delante de un diptongo creciente que comience por /i/). Se trata de una variante contextual muy frecuente, aunque el hablante puede elegir pronunciar las vocales en diptongo o en hiato, lo cual conllevaría la realización de [1] en lugar de $[K]$. También dependerá del hablante pronunciar [li] o [Ki] en otro entorno que no sea un diptongo. Por ejemplo, podemos escuchar la palabra $\lambda ı$ ıó $\varsigma$ 'sencillo' como [litós] o [Kitós]; esta última, sin embargo, es evitada por personas de más alto nivel sociocultural ya que está estigmatizada socialmente, consideración que no afecta al primer caso.

Por otro lado, la pronunciación general de la " $\mathrm{r}$ " es [r] "floja" (con un solo choque del ápice de la lengua contra los alvéolos) en cualquier posición fonotáctica, incluso en la inicial. Sin embargo, en una pronunciación marcada, podemos oír una $[\mathrm{r}]$ tensa, realizada con más de una vibración, sobre todo en canciones. Algunos griegos - pocos- tienden a pronunciarla de este modo. En ningún momento la realización de una u otra diferencia significados.

\section{LAS NASALES GRIEGAS Y ESPAÑOLAS}

En lo que respecta a los sonidos nasales, de especial interés en nuestro estudio, lo primero que debemos tener presente es que en ambas lenguas aparecen los sonidos nasales labial [m], alveolar [n] y palatal [n]. Además del lugar de salida del aire (resonador de las fosas nasales), todos ellos tienen en común la sonoridad que les aportan las vibraciones de las cuerdas vocales. Pero si hablamos de fonemas, existen tres de este tipo en español y solo dos en griego (Tabla 2).

\begin{tabular}{|c|c|c|}
\hline Nasales & GRIEGO & ESPAÑOL \\
\hline$/ \mathrm{m} /$ & $\begin{array}{l}\text { movó } \delta \alpha / \text { monáđa/20 ‘unidad', } \\
\text { кó } \mu \alpha / \text { kóma/ 'partido' }\end{array}$ & música $/ \mathrm{m} /$ úsica, cama ca/m/a \\
\hline$/ \mathrm{n} /$ & vió $\tau \alpha /$ niáta/ 'juventud', vovóৎ/nonós/ 'padrino' & nunca /n/unca, cenit ce/n/it \\
\hline$/ \mathrm{n} /$ & & niño ni/n/o, ñoño $/ \mathrm{g} / \mathrm{o} / \mathrm{n} / \mathrm{o}$ \\
\hline
\end{tabular}

Tabla 2. Fonemas consonánticos nasales del griego y del español

Estos fonemas se diferencian unos de otros en el punto de articulación: bilabial para $/ \mathrm{m} /$, alveolar para $/ \mathrm{n} / \mathrm{y}$ palatal para /n/. Las variaciones del lugar donde se produce la fonación de las nasales cuando aparecen en contigüidad con otras consonantes serán tratadas en el apartado siguiente; solo mencionaremos que las tres mantienen el rasgo distintivo que marca su carácter nasal común.

A pesar de que en griego no existe el fonema /n/, sí cuentan con el sonido [n] como variante combinatoria cuando la $n$ antecede a un diptongo creciente que comienza por [i]; así la transcripción fonética de vió $\alpha$ es [náta]. En caso de que a la /n/ le siga la /i/ y luego pausa o consonante, también puede producirse una palatalización de la nasal. No obstante, esta última se acompaña de marcas sociolingüísticas: es propia de una pronunciación descuidada,

20 Para no distraer la atención en fenómenos que no afectan a las nasales, no transcribiremos fonológica (ni fonéticamente) toda la palabra ejemplificada en español sino solo la nasal u otro sonido que queramos destacar especialmente. Sí anotamos la transcripción completa en las palabras griegas para no recurrir a una transliteración ortográfica al español. 
al igual que ocurre - como ya hemos visto - con la palatalización de [1], articulada como [ $K]$

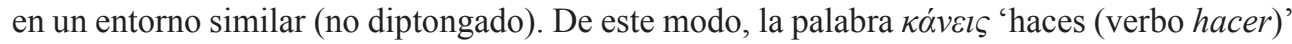
puede ser pronunciada [kánis] o [kánis]. Con la otra vocal palatal e no ocurre lo mismo, de ahí que la segunda persona del plural del verbo $\kappa \alpha ́ v \omega$, antes mencionado ( $\kappa \alpha ́ v \varepsilon \tau \varepsilon$ 'hacéis') se pronuncie [kánete] en todos los casos.

\section{LA ALOFONÍA EN LAS NASALES DEL GRIEGO Y DEL ESPAÑOL: VARIA- CIÓN Y VARIEDAD}

Las nasales se diferencian unas de otras, en ambas lenguas, por el punto de articulación. Cuando a estos fonemas les sigue otra consonante, el lugar de la fonación varía automáticamente dando lugar a sonidos diferentes que se aproximan más o menos a uno de los fonemas nasales o sus alófonos. De este modo, [n] aparecerá ante una dental; [m], ante una labial; [y], ante una velar; etc. Como esta alofonía diferenciada solo responde al contexto fonotáctico, pierde su función contrastiva y las variantes se neutralizan. El único rasgo distintivo es el carácter nasal común a $/ \mathrm{m} /, / \mathrm{n} /, / \mathrm{n} /$ (para el español) y sus alófonos, que queda representado en el archifonema $\mathrm{N}^{21}$.

Detengámonos en las nasales del español y su alofonía, rica en variantes:

- Para /n/ existen: la nasal, alveolar, sonora [n] en cualquier posición, excepto ante $c a$, $c o, c u, c+$ consonante, $q, k, g, j, d, t, c e, c i, z$ (en zonas no seseantes) (nena [n] [n] a, enredo $\mathrm{e}[\mathrm{n}]$ redo, conserva co[n]serva, tacón tacó[n]); la nasal, interdental, sonora $\left[\mathrm{n}^{\theta}\right]$ ante $c+e, i$ у $z$ (en zonas no seseantes) (onza o[n $\left.\mathrm{n}^{\theta} \theta\right] \mathrm{a}$ ); la nasal, dental, sonora [n] ante $d$, $t$ (anda a[n.d] a); la nasal, velar, sonora [y] ante $c a, c o, c u, c+$ consonante, ga, go, gue, gui, güe, güi o consonante, ge, gi, $j$, que, qui y $k$ (cinco ci[nk]o); la nasal, labiodental, sonora [m] ante $f$ (enfado e[mf]ado) y la nasal, bilabial, sonora [m] ante $b, v$ y $p$ (invento i[mb]ento).

- Para /m/: la nasal, bilabial, sonora [m] en cualquier posición (mamá [m]a[m]á, comba co[mb]a) y $n$ ante $b, v$ y $p$ (invento i[mb]ento).

- Para /n/, la nasal, palatal, sonora [n] en cualquier posición (caña ca[n]a).

Las nasales en posición implosiva presentan gran variedad en español teniendo en cuenta las diferentes realizaciones idiosincrásicas de sus variedades dialectales. Casado y Andión (en prensa) comentan, tras un detallado estudio del panorama dialectal del español, los fenómenos más extendidos: "el debilitamiento nasal, con asimilación ante consonantes, la conservación de la alveolar ante vocales o pausa y la incipiente elisión”. Afirman las autoras que la velarización de /n/ implosiva en fonotaxis es abundante ante vocal y pausa como muestra del debilitamiento que alcanza a las consonantes en esa posición. Se puede oír en el norte y occidente de España (Galicia, León y Extremadura), Madrid y, sobre todo, en Andalucía y Canarias (RAE y ASALE 2011: 241).

También es frecuente en español la pérdida de $/-n / 22$, distribuida en diferentes grados según geolectos. Esta aparece más acusada en las áreas lingüísticas innovadoras de España,

21 El archifonema es una entidad definida por un conjunto de rasgos comunes a dos o más fonemas cuya oposición queda neutralizada (Martinet 1936: 54). El lingüista francés (op. cit. 1968: 98-99) ejemplifica el concepto justamente con las nasales $/ \mathrm{n}, \mathrm{m}, \mathrm{n} /$. No reflejamos los archifonemas en las transcripciones porque carece de importancia en este trabajo.

22 Con la raya delante de la representación fónica, en todos casos en los que se use, queremos señalar su posición final. 
el Caribe continental e insular americanos, que penetra en Centroamérica (excepto centro y norte de México, donde predomina la /-n/ alveolar) y las costas de Suramérica, con nasalización de la vocal que constituye el núcleo de la sílaba de la consonante nasal. Mientras, las zonas altas andinas retienen la realización de [n] alveolar, con áreas de transición en las que conviven ambas variantes (Casado y Andión, en prensa).

El español de los EE. UU. no queda exento de variaciones en cuanto a la realización de las nasales se refiere. El español patrimonial realiza la /n/ alveolar en posición final absoluta (Texas, Nuevo México, Colorado y Arizona) con algunas velarizaciones. Luisiana, por ejemplo, documenta velares con nasalización de la vocal precedente (Alvar 2000; Casado y Andión, en prensa; McCurdy 1975).

Zonas más aisladas, como Filipinas, la República Árabe Saharaui Democrática y Guinea Ecuatorial, se muestran conservadoras realizando preferentemente /-n/ alveolares (Quilis y Casado 1995; Quilis y Casado 2008; Tarkki 1995).

También aparece la variante de /-n/ labializada [-m] en amplias zonas de México (sobre todo Yucatán) y Colombia, y de forma aislada en Paraguay y Argentina (Casado y Andión, en prensa).

En el español de la zona austral y Chile suelen predominar las realizaciones alveolares de /-n/ (Alvar 2000; Lipski 2005 [1996]).

Las realizaciones correspondientes a la posición inicial, aunque menos variable dialectalmente en español, no deja de ser interesante. Casado y Andión (en prensa) reconocen procesos inversos muy extendidos por el mundo hispánico: de palatalización, despalatalización, nasalización y desnasalización.

Las variedades de Asturias, Castilla y León y Castilla-La Mancha (España) palatalizan $[\mathrm{n}-]^{23}$ en $n i$ : [n]ube nube (Moreno 1996; Quilis 1999); las americanas de los EE. UU. (Nuevo México), México (Jalisco), Puerto Rico (Ponce), Colombia, Ecuador (sierra), Bolivia, Chile y Argentina, más Guinea Ecuatorial y Filipinas, completan el proceso en [n]: [n]eves nieves (Montes Giraldo 1962; Quilis 1999; Quilis y Quilis Sanz 2003). La palatalización es especialmente interesante si tenemos en cuenta las condiciones descritas más adelante, en que aparece [n] como variante de $/ \mathrm{n} /$ en griego.

La despalatalización de /n/, fenómeno no ajeno al griego para el fono [n], se produce en variedades españolas, americanas y africanas: Andalucía, Extremadura, México, Centroamérica, Ecuador, Argentina, Guinea Ecuatorial (mo[nio] moño, pa[n]uelo pañuelo) (Casado y Andión, en prensa; Córdova 1996; Moreno 1988 y 2010; Quilis 1999; Quilis y Casado 1995).

Por su parte, los procesos de nasalización y desnasalización son escasos pero se dan en diferentes variedades del español con las que el aprendiz griego o el docente puedan tener contacto. En el caso de este último, podría ser casualmente de una procedencia dialectal con esos fenómenos lingüísticos. La nasalización es frecuente en el Caribe y Perú, sobre todo en contacto con una aspirada, que nasalizaría la vocal anterior: virgen vi[yh]en virgen (Caravedo 1990; Lipski 2005 [1996]).

Las palatales $/ \mathrm{j} / \mathrm{y} / \mathrm{t}$ / se nasalizan con bastante frecuencia tanto en España (Asturias y León) como en América (Ecuador) y África (Guinea Ecuatorial): [n]ema yema, [n]ato chato (Casado y Andión, en prensa; Quilis y Casado 1995). Fenómeno más intenso y dialectal que el que veremos luego en el griego.

23 Con la raya delante de la representación fónica, en todos casos en los que se use, queremos señalar su posición inicial. 
También puede producirse la desnasalización de /n/ por pérdida de la oclusión oral que queda solo con sus rasgos palatales y que se da en diferentes grados: se[j $\left.\mathrm{j}^{\mathrm{n}}\right]$ al señal, [j]ame ñame. Se puede oír en El Salvador, Cuba (zona occidental), Colombia, Ecuador, Perú, Bolivia, Guinea Ecuatorial, Filipinas (Canfiel 1960; Quesada 2000; Quilis 1995; Quilis y Casado 1995; Quilis y Casado 2008; Quilis y Quilis Sanz 2003).

Por su parte, las nasales de las secuencias $n s C, m n, n m, m b, m p$ (menos $g n$ ), ya sean tauto o heterosilábicas, participan en procesos simplificadores y velarizadores generalizados en las variedades españolas y americanas: i[s]tituto instituto, alu[n]o alumno, e[m]ascarado enmascarado, ['inno] himno, ta[m]ién también, e[yp]inar empinar (Casado y Andión, en prensa). Esto no ocurre nunca en griego, salvo en el caso que veremos más adelante de la pérdida de la nasal tras la sonorización de un fonema sordo.

En griego, las variantes son algunas menos, coinciden con las del español castellano (centro-norte peninsular), sumando el alófono de /n/ [n] a las que se describen a continuación:

- Para /m/: la nasal, bilabial, sonora [m] en todas las posiciones, menos ante labiodental

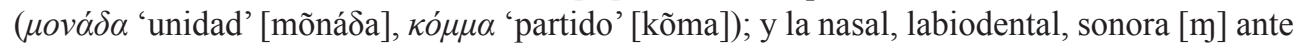
labiodentales ( $\alpha \mu \varphi \imath \beta \alpha \dot{\lambda} \omega \omega^{\prime}$ 'dudar' [amfiválo]).

- Para /n/: la nasal, alveolar, sonora [n] en cualquier posición (vovó ` 'padrino' [nonós]); la nasal, interdental, sonora $\left[\mathrm{n}^{\theta}\right]$ ante interdental ( $\alpha v \theta i \zeta \omega$ 'florecer' [an $\left.\left.{ }^{\theta} \theta i ́ z o\right]\right)$; la nasal, dental, sonora [n] ante dental ( $\alpha \dot{v} \tau \rho \alpha \varsigma$ 'hombre' [ándras] $\left.{ }^{24}\right)$; la nasal, velar, sonora [n] ante una velar ( $\alpha \gamma \chi o \varsigma$ 'estrés' [ánxos]); la nasal, bilabial, sonora [m] ante bilabial ( $\mu \eta v \mu \pi \varepsilon ı \varsigma$ 'no entres' [mịmbịs] $]^{25}$ ); y la nasal, palatal, sonora [n] ante $i+$ vocal (vió $\alpha \alpha$ 'juventud' [náta]).

\subsection{Influencia del contexto en las nasales del griego}

Lo más llamativo de las nasales griegas, en contraste con las de la lengua española, es la aparición del sonido palatal sonoro [n] ante la vocal de abertura mínima y de localización anterior o palatal /i/, seguida de otra vocal en las cuatro posibles combinaciones de diptongos griegos [ia], [ie], [io], [iu]: vı́́ $\tau \alpha$ 'juventud' [náta]. A veces, también encontramos palatalización nasal por contacto solo con la vocal /i/, como variante libre seguida de consonante o pausa: $\Pi \alpha v i$ [paní]-[paní]. Por último, aparece la palatal [n] cuando la nasal se pone en contacto con el fonema griego africado, palatal, sonoro $/ \overline{d j}$ ! o el africado prepalatal sordo $/ \mathrm{tf} /$.

$\mathrm{Al}$ igual que en algunas variedades del español, también en griego se puede dar la despalatalización del sonido [n]. Son, en cualquier caso, fenómenos concretos debidos a la pronunciación en hiato del diptongo que sigue a la nasal por alguna razón circunstancial. A diferencia del español, como ya mencionamos, el sonido [n] no pertenece al sistema fonológico del griego, por lo que su articulación - o no- es indiferente para la comprensión de lo emitido.

24 Existe la variante $\alpha ́ v \delta \rho \alpha \varsigma$ [áñ $\delta$ ras], de menor frecuencia y mayor dificultad, ya que la demótica (variedad hablada de la lengua griega moderna) no admite un sonido fricativo tras nasal. En la variedad culta, la katharévousa, que surgió a finales del siglo XVIII como intento de purificar la lengua, sí que existía dicha combinación al igual que en el griego clásico. Tras años de controversia y situación diglósica, en 1976 se impuso la variedad popular (demótica o dimotikí) frente a la culta arcaizante (katharévousa), pasando a ser la lengua oficial del Estado, la que se enseña hoy en día en todo el territorio griego. A pesar de todo, existen reminiscencias de katharévousa en textos escritos y registros cultos tanto a nivel léxico como morfológico o fonético.

25 También existe la variante con la nasal elidida [mịbịs]. 


\subsection{Influencias de las nasales del griego en el contexto consonántico}

Cuando a una nasal le sigue un fonema sordo $/ \mathrm{p}, \mathrm{t}, \mathrm{k}, \overline{\mathrm{t}} /$, este se sonoriza dando lugar a $[\mathrm{b}, \mathrm{d}, \mathrm{g}, \widetilde{\mathrm{dj}}]$ que, además de fonemas independientes, son también variantes combinatorias de los fonemas sordos anteriores tras nasal. En particular, los sonidos bilabiales [p] y [b], tras una nasal, son variantes del mismo fonema /p/. El sonido habitual es [b]; cuando se realiza como [p], es mera variante libre debida a un esfuerzo articulatorio del hablante en registros cultos principalmente por razones etimológicas.

La frecuencia de la sonorización llega a afectar a casos como el del vocablo $\pi \rho i \zeta \alpha$ 'enchufe' [príza], del francés prise, que por influencia del artículo en acusativo regido por la preposición en, propio de contextos como 'conectar, meter en el enchufe', posee una segunda forma $\mu \pi \rho i \zeta \alpha$ [bríza]. La sonora [b] aparece mucho más generalizada para cualquier contexto, incluso cuando el artículo va en nominativo, en cuyo caso no existiría la nasal:

(1) $B \alpha ́ \zeta \omega \sigma \tau \eta v \mu \pi \rho i \zeta \alpha$ 'enchufar' [știmbríza] o [stibríza]

$H \mu \pi \rho i \zeta \alpha$ "el enchufe" [ibríza]

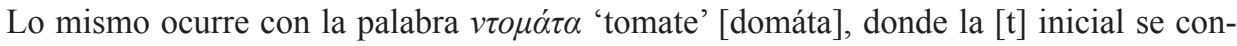
vierte en $[\mathrm{d}]$, etc.

También debemos detenernos en el caso de la $/ \widehat{\mathrm{tg}} / \mathrm{y}$ la $/ \overparen{\mathrm{dj}} /$ en contacto con la nasal. En español hemos visto que una nasal ante $\overparen{\mathrm{t} \int}$, se palataliza, por ejemplo en la palabra

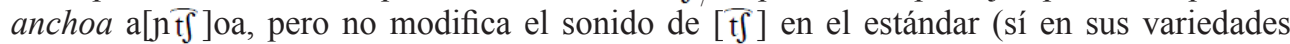
dialectales). En griego, además de la palatalización de la nasal, y al igual que en los otros fonemas sordos, la [ $\overline{\mathrm{t}}]$ se sonoriza tras nasal y se convierte en [ [dj]. Pero este idioma, aunque cuenta con bastantes palabras que contienen [n $\overparen{d j}]$, no dispone de vocablos con [n $\widetilde{\mathrm{t}}$ ], salvo en algún préstamo. Es el caso de $\alpha \nu \tau \sigma o v ́ \gamma \alpha$ 'anchoa', en el que aparece [n $\widehat{\mathrm{t}}]$ ] (si hablásemos siguiendo la ortografía), pero la nasal sonoriza la $\overparen{\mathrm{tg}} /$ en [ $\overparen{\mathrm{dj}}]$ en el habla; así,

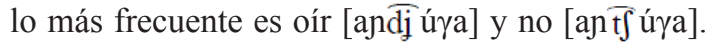

Los grupos ortográficos $\mu \pi, v \tau, \gamma \gamma, \gamma \kappa$ se realizan como $[b, d, g]$ oclusivos si son iniciales absolutos, posición en la que aparece la nasal solo en la escritura. Sin embargo, en el interior de la palabra, estos grupos van precedidos por la articulación de la nasal correspondiente [mb], [nd], [ng] y casi nunca - salvo en una pronunciación forzada- escuchamos la sorda tras la nasal, como en [mp], [nt], [yk]. Sirvan de ejemplos: $\kappa o \mu \pi \lambda \varepsilon ́$ 'completo' [komblé],

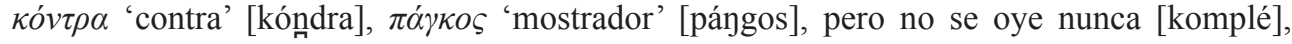
[kóntra], [páykos], como cabría esperar atendiendo a la etimología.

La nasal de estos grupos en interior de palabra puede sufrir diferentes grados de reducción, dependiendo del idiolecto del hablante, y llegar incluso a desaparecer. Debemos advertir de que no tiene ningún valor distintivo el que se oiga o no la nasal. Quedan, entonces, las oclusivas sonoras [b], [d], [g], [đj] ] en, por ejemplo, $\mu \pi \alpha \mu \pi o v$ 'bambú' [babú] y

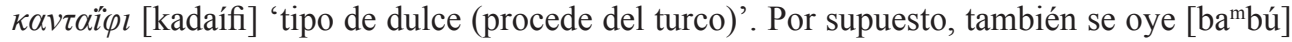
y [kan daífi] o, con menor frecuencia [bambú] y [kandaífi].

Como hemos comentado, la realización de las sordas en lugar de las sonoras es un intento correctivo un tanto artificial, posible en contadas ocasiones, sobre todo en préstamos y en palabras compuestas (Danelis 1988: 170). De ahí que también oigamos [ẹkároios] para

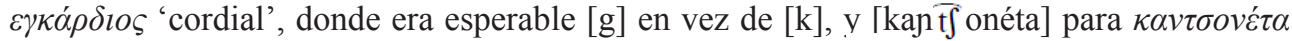

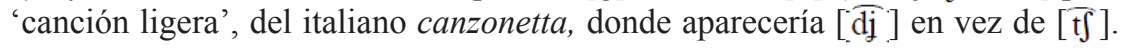

Cuando la unión de la nasal y la sorda resulta de una síncopa, es algo más frecuente que se conserve el sonido sordo. Véase el caso de los imperativos seguidos de un pronombre 
átono enclítico: $\kappa \alpha ́ v \varepsilon$ 'haz', imperativo del verbo $\kappa \alpha ́ v \omega$ 'hacer', y $\tau o$ 'lo', pronombre complemento directo; al unirse, desaparece la $\varepsilon$ y queda $\kappa \alpha v^{\prime} \tau o$ 'hazlo' [kánto] ${ }^{26}$. Por el contrario, es infrecuente la desaparición de la nasal como en [kádo]. De todas formas, la sonorización de las sordas tras nasal es el fenómeno más extendido.

Para concluir, la fricativa, interdental, sorda $/ \theta /$ se sonoriza en [z] si le sigue, además de

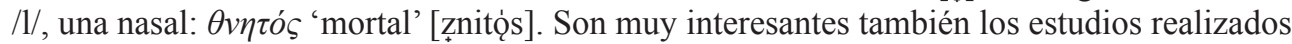
sobre este tema y que atañen a otros dialectos como el de Creta, donde desaparece la nasal ante $[\mathrm{b}, \mathrm{d}, \mathrm{g}, \widetilde{\mathrm{dj}}]$ (Tsakona 2007) o como el chipriota, en el que, paradójicamente, aparece siempre en el mismo contexto una nasal más o menos marcada (Makri 2015) 27. Pero, como ya indicamos, el entrar en otras variedades del griego supera las expectativas de este trabajo.

\section{CONSIDERACIONES PARA LA ENSEÑANZA DE NASALES DEL ESPAÑOL A APRENDICES GRIEGOS}

Cuando aprendemos una lengua segunda o extranjera, solemos trasladar el sistema nativo y sus variantes fonotácticas a la nueva lengua. Muchas veces los alófonos vienen dados y no tenemos potestad de elegir; ni tan siquiera los nativos ${ }^{28}$ tienen conciencia de que existan esas adaptaciones al contexto fónico. Lo que no es percibido como variante en la lengua materna, continúa sin serlo en la segunda. Esto da lugar a errores que incluso pueden llegar a interrumpir la comunicación.

Respecto de las nasales y otros sonidos vinculados fonotácticamente, de especial interés en este trabajo, debemos partir de reconocer la complejidad de variantes que presenta el español respecto del griego. Alertamos a los docentes sobre que es esperable que estos hablantes transfieran a la pronunciación con dificultad las diferencias con las que tienen que articular las letras del español correspondientes a /b/, /mb/,/mp/, /d/,/nd/, /nt/; así como que tampoco suelen distinguir en la lengua hablada $/ \mathrm{g} /, / \mathrm{nk} /, / \mathrm{ng} /$. Ello ocurre porque la pronunciación en griego de los grupos gráficos $\mu \pi, \nu \tau, \gamma \kappa, \gamma \gamma$ equivale a sonidos oclusivos: [b] en $\mu \pi$, [d] en $v \tau$ y [g] en $\gamma \kappa$ y $\gamma \gamma$. Sin embargo, en numerosas ocasiones, especialmente cuando estos se encuentran en posición interior de palabra (no inicial) y tras vocal, aparecerá una nasal más o menos marcada.

También, como los sonidos sordos $[\mathrm{p}, \mathrm{t}, \mathrm{k}]$ se sonorizan, producen $[\mathrm{b}] \mathrm{o}[\mathrm{mb}] \mathrm{o}\left[{ }^{\mathrm{m}} \mathrm{b}\right],[\mathrm{d}]$ o [nd] o [ $\left.{ }^{\mathrm{n}} \mathrm{d}\right],[\mathrm{g}]$ o [ng] o [ $\left.{ }^{\mathrm{n}} \mathrm{g}\right]$. En este último caso, la interferencia sería más fuerte pues la nasal y la oclusiva siempre van unidas en la misma sílaba en griego; son una única realidad sonora y nunca aparecen en sílabas separadas pues corresponden a un único fonema. De ahí las dificultades fonéticas y ortográficas de los griegos con palabras que presentan esas secuencias consonánticas en español (cobra, compra, sombra, sobra, cuando, cuanto, antro, canto, dentro, flamenco, etc.). Lo habitual es que realicen oclusivos sonoros los sonidos [b,

26 También encontramos [kándo].

27 Para más detalles sobre este fenómeno y la dificultad de comprensión que conlleva cuando el grecochipriota habla en español, remitimos al mismo autor.

28 Es necesario aclarar que consideramos nativo de una lengua no solo a quien la ha aprendido como primera en orden cronológico (L1 o lengua materna), como lo entendía Bloomfield (1933), sino a quien tiene un dominio (competencias oral y escrita) como naturalmente equivalente si ese hubiera sido el caso, como más adelante lo definieron Dubois et alii (1973). En un sentido estricto (cronológico) o amplio (de dominio), un hablante puede tener varias L1. Siendo frecuente la coexistencia de lenguas naturales, a lo que se añade el fenómeno de movimientos migratorios de personas, el plurilingüismo es una situación habitual en los grupos humanos. 
$\mathrm{d}, \mathrm{g}]$ y añadan una nasal, al igual que en griego. Por ejemplo, cobra y compra pueden ser articuladas con $[\mathrm{b}]$ o [ $\left.{ }^{\mathrm{m}} \mathrm{b}\right]$ o [mb], por lo que el par cobra/compra deja de ser distintivo.

Así lo hacen constar Leontaridi et alii (2009) en su análisis de un corpus compuesto por 93 muestras de textos pertenecientes a la Prueba 2 de Expresión escrita de los exámenes del Diploma de Español como Lengua Extranjera (DELE) Básico -equivalente al actual DELE Intermedio-, realizada en Atenas (Grecia). Las autoras (2009: 15-16) citan, entre los errores relacionados con la fonética y el uso del alfabeto, el seseo ${ }^{29} \mathrm{y}$ "otros casos interesantes que [...] incluyen la sustitución de $<\tilde{\mathrm{N}}>$ por la secuencia $<\mathrm{NI}>$ : seniora [señora]" y la "neutralización de $<\mathrm{D}>$ por $<\mathrm{NT}>$ : cuanto [cuando], ademano [antemano]". Estos últimos involucran las nasales con una representación en su corpus de un $8 \%$ cada fenómeno.

De ahí que, desde un primer momento, los docentes de ELE debamos insistir en varias cuestiones. Primera, que la diferencia entre los grafemas $b$ y $v$ es exclusivamente ortográfica y no fonética. Se pronuncian exactamente igual en cualquier entorno. Es importante recalcar que la letra $v$ en posición inicial absoluta o precedida de consonante nasal, corresponde siempre a las grafías griegas $\mu \pi$ (Kouti 2005: 297), cuya pronunciación es el oclusivo [b] y no el fricativo [v], al igual que ocurre con la letra $b$ en el mismo entorno (Hernández de la Fuente 2001, Kouti 2006).

Segunda, que salvo en el caso anterior (tras nasal o en posición inicial absoluta ${ }^{30}$, en el que además de [b] oclusiva para los grafemas $b, v$, aparecen también las variantes oclusivas [d] y [g] para $d$, g), es preferible la realización de los fonemas fricativos griegos correspondientes a los grafemas $\beta, \delta, \gamma$ cuando aparecen en español $b, v, d, g$, pues se parecen más a los sonidos aproximantes de un hispanohablante (Hernández de la Fuente 2001). En estas explicaciones recomendamos huir del metalenguaje filológico, podemos circunscribirnos a sugerir que estas realizaciones sean más suaves y relajadas. Además, evitaríamos la aparición de nasalizaciones, que solo acompañan las realizaciones oclusivas.

Y tercera, cuando aparece una nasal ante estos fonemas, deben aprender a aplicar una correcta segmentación silábica en español, separando la nasal (sílaba anterior) de la consonante siguiente (sílaba posterior) ${ }^{31}$. En nuestra opinión, esta es la forma más eficaz de conseguir que los aprendices griegos separen las oclusivas, bien sordas o bien sonoras, de la nasal que las precede.

\section{CONCLUSIONES}

Partimos de la afirmación de que los problemas de pronunciación, tanto para un grecohablante que aprende español como para un hispanohablante que hace lo propio con el griego, son escasos y fácilmente superables. Aunque no todos los errores fonéticos de sus respectivas interlenguas los causan las interferencias de la lengua materna, la gran mayoría se explica por transferencias negativas. La primera evidencia se produce al comprobar las

29 El uso de "errores" se refiere a la escritura de las palabras en los exámenes, tras los que suponen fenómenos subyacentes como el seseo (ejemplos citados: *prestasiones (prestaciones), *capasidad (capacidad), *vacasiones (vacaciones) [Leontaridi et alii. 2009: 16]). En ningún caso las autoras suponen que el seseo sea un error de pronunciación, muy por el contrario, lo reconocen como un fenómeno oral de gran extensión geolectal en español. 30 Según nuestra experiencia, es más práctico y efectivo referirse solo al caso "tras nasal”. Al igual que está de más - al menos en los primeros estadios de aprendizaje- mencionar que en español la pronunciación de /d/ es oclusiva cuando va precedida del fonema lateral /1/.

31 Para ampliar esta información, remitimos a Kouti (2010). 
ausencias en las correspondencias fonológicas de las dos lenguas, lo que condiciona que "los aprendientes de una L2 tendrán mayor dificultad con los fonemas ausentes en la L1 que con el sonido de la L2 similar a otro de la L1" (Lado 1957: 13).

En el proceso de enseñanza, los docentes debemos ser conscientes de esas diferencias para que los aprendices puedan superar los posibles errores y evitar la fosilización. En el caso del griego y el español, es importante contar con el referente escrito para apoyar buenas prácticas de pronunciación ya que ambas lenguas tienen una escritura fonográfico-alfabética y tienden a la correspondencia - aunque no siempre biunívoca- entre fonemas y letras. Pero, obviamente, hablamos de sistemas fonológico-fonéticos diferentes por lo que los errores, más o menos graves, pueden afectar en la misma medida la transmisión del mensaje y hacer peligrar la comunicación. Los errores que solo muestran el acento de procedencia sin alterar la comunicación no tienen la misma relevancia. No obstante, en nuestra experiencia, los aprendices griegos aprecian el cuidado ortofónico y también deberíamos ayudarlos a tener una pronunciación cuidada.

Estas reflexiones permiten concluir que la inclusión o elisión de las nasales en la articulación de las oclusivas es de los casos más distorsionantes en la producción de los aprendices griegos que se acercan al español. Que no pronuncien la nasal correspondiente delante de la oclusiva española o que sonoricen la sorda posterior a la nasal provoca consecuencias negativas de incomunicación. Insistir en el carácter fricativo mayoritario de los sonidos correspondientes a $b, v, d, g$ (salvo si van precedidos de nasal) suele ser la solución. También lo es separar silábicamente las nasales cuando aparecen ante /b/, /d/, /g/ y /p/, /t/, /k/ para retener su articulación. No obstante, llamamos la atención sobre la existencia de ciertos modelos dialectales hispánicos en los que la nasal se pierde (variedades innovadoras de España, el Caribe continental e insular, Centroamérica - excepto centro y norte de México- y costas de Suramérica) y que deben ser considerados según el contexto y otras circunstancias de aprendizaje. Del mismo modo, hacíamos referencia somera a algunos dialectos del griego -como el hablado en Chipre o en Creta- en los que nos encontramos intensificados estos fenómenos, aspectos que conviene tener en cuenta en futuras investigaciones por el interés que suscitan de cara a la enseñanza de ELE.

Otras interferencias en la pronunciación se resuelven de la misma manera, distinguiendo los sonidos, como en los diptongos crecientes que siguen a /1/ o /n/ (familia o nieta), palatalizados frecuentemente en $[K]$ o [n]. Una forma de corrección es indicarles a los aprendices que los pronuncien en hiato. Pero no olvidemos que en el español europeo, americano, africano y asiático, se producen casos de palatalización de /n/ en [n], tan similar a la variante griega de $/ \mathrm{n} /$.

Asimismo, es fundamental que palatalicen la nasal de la sílaba $\tilde{n} i$ del español (pequeñito), pues $/ \mathrm{n} / \mathrm{y} / \mathrm{n} /$ son dos fonemas bien diferenciados en español, lo que no impide que variedades españolas, americanas y africanas recojan el fenómeno despalatalizador (Andalucía, Extremadura, México, Centroamérica, Ecuador, Argentina, Guinea Ecuatorial). No debe olvidarse el añadido sociolingüístico de que, salvo en el caso de los diptongos crecientes, la combinación [ni] en griego está muy estigmatizada socialmente.

En lo que se refiere a las nasales y sus contextos, estos fenómenos son los más frecuentes y evidentes en aprendices grecohablantes de ELE. Esperamos que nuestras reflexiones, resultado de una mesurada investigación y experiencia continuada, sean de utilidad e interés para abordar la enseñanza de estos aspectos fonéticos del español a estudiantes de lengua materna griega. 


\section{REFERENCIAS BIBLIOGRÁFICAS}

Alvar López, M. (2000). "Muestras de polimorfismo en el español de la Argentina”. En Alvar, M. América. La lengua. Valladolid: Universidad de Valladolid, pp. 315-347.

Andión Herrero, M. ${ }^{\text {a }}$ A. y C. Casado Fresnillo (2014). Variación y variedad del español aplicadas a $E-L E / L$, Madrid: Editorial UNED (libro electrónico).

Bloomfield, L. (1933). Language. New York: Henry Holt.

Brasil. Lei 11.161. Dispõe sobre o ensino da língua espanhola. Diário Oficial [da República Federativa do Brasil], Brasília, D. F., 8 de agosto de 2005, p. 1.

Canfield, D. L. (1960). “Observaciones sobre el español salvadoreño”, Filología, 6, pp. 29-76.

Caravedo Barrios, R. (1990). Sociolingüística del español de Lima. Lima: Pontificia Universidad Católica del Perú.

Casado Fresnillo C. y M. ${ }^{a}$ A. Andión Herrero (en prensa). "Capítulo 13: La variación en las consonantes oclusivas nasales del español”. En Gil, J. y J. Llisterri (coords.). Fonética y Fonología descriptivas de la Lengua Española. Madrid: CSIC.

Castellanos Vega, I. (2006). "Análisis de necesidades e implicaciones a nivel institucional del área geográfico-cultural, de centro y de aula". Tesis doctoral. Revista electrónica de didáctica del español lengua extranjera (redELE), 6: http://www.educacionyfp.gob.es/educacion/mc/redele/biblioteca-virtual/numerosanteriores/2006/memoriamaster/2-semestre/castellanos-v.html (22-04-2019).

Chatzes, S. (2017). "Lengua Española: Una valoración de la situación en Grecia”, Ispania: https:// www.ispania.gr/arthra/ispanika/5802-ispaniki-glossa-mia-ektimisi-tis-katastasis-stin-ellada (1101-2018).

Córdova, C. J. (1996). “Ecuador”. En Alvar, M. (dir.). Manual de dialectología hispánica. El español de América. Barcelona: Ariel, pp. 184-195.

Danelis, E. (1988). "Notas sobre la fonética del griego moderno, I. Silbantes y grupos de oclusiva y silbante", Erytheia, 9.1, pp. 167-175.

Dubois, J., M. Giacomo, L. Guespin, C. Marcellesi, J.-B. Marcellesi, J.-P. Mével. (1973). Diccionario de lingüística. Madrid: Alianza Editorial.

Edinumen (2009). "El español en... GRECIA". Entrevista a la profesora Natividad Peramos. CampusProfELE: https://www.edinumen.es/index.php?option=com_content\&view=article\&id=130\&catid $=16$ :espanol-en-el-mundo\&Itemid=50 (07-11-2015).

Fernández, S. (1997). Interlengua y análisis de errores: en el aprendizaje del español como lengua extranjera. Madrid: Edelsa.

Fries, C. C. (1945). Teaching and Learning English as a Foreign Language. Michigan: The University of Michigan Press.

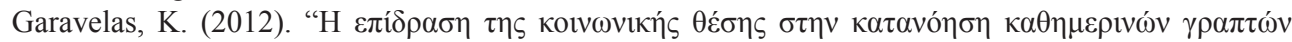

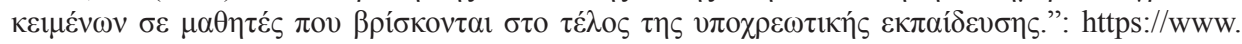
researchgate.net/publication/291971603_E_epidrase_tes_koinonikes_theses_sten_katanoese kathemerinon_grapton_keimenon_se_mathetes_pou_briskontai_sto_telos_tes_ypochreotikes_ ekpaideuses (31-08-2018).

Hernández de la Fuente, D. H. (2001). "Lingüística contrastiva hispano-helénica: una aproximación a la enseñanza del español a hablantes de griego moderno", Cuadernos Cervantes, 32, pp. 19-31: http:// www.cuadernoscervantes.com/lc_griego.html (11-04-2019).

Instituto Cervantes (2018). El español: una lengua viva. Madrid: Departamento de Comunicación Digital del Instituto Cervantes: https://cvc.cervantes.es/lengua/espanol_lengua_viva/pdf/espanol_ lengua_viva_2018.pdf (20-04-2019).

Kouti, M. (2005). "El español en Grecia: Principales dificultades de los estudiantes griegos en el aprendizaje de E/LE". En Saz, S. M. (ed.). Actas de XL Congreso Internacional de la Asociación Europea de Profesores de Español. 400 años de Don Quijote: pasado y perspectivas de futuro. Chile: AEPE, pp. 293-304. 
Kouti, M. (2009). "Entrevista a Eusebi Asenya Prat, Director del Instituto Cervantes en Atenas", Ispania.: https://www.ispania.gr/arthra/diafora/825-syneneteyxi-eusebi-ayensa?showall=\&start=1 (10-01-2018).

Kouti, M. (2010). "Problemas perceptivos de la estructura silábica del español por aprendices griegos de E/LE", Revista electrónica de didáctica del español lengua extranjera (redELE), 7(19): http:// www.mecd.gob.es/dctm/redele/Material-RedEle/Revista/2010_19/2010_redELE_19_01Kouti.pdf ?documentId=0901e72b80dd2432) (18-01-2018).

Lado, R. (1957). Linguistics Across Cultures: applied Linguistics for Language Teachers. Michigan: The University of Michigan Press.

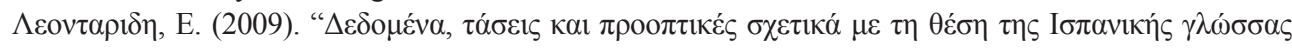

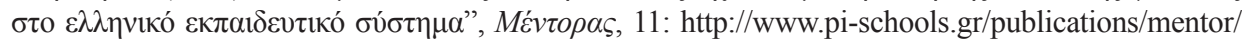
[Leontaridi, E. (2009). "Datos, tendencias y perspectivas en relación con la situación del español en el sistema educativo griego", Mentor, 11: http://www.pi-schools.gr/publications/mentor/] (20-01-2018).

Leontaridi, E., N. Peramos Soler y M. Ruiz Morales (2009). "Errores en la interlengua escrita de estudiantes grecófonos de español como lengua extranjera”, Zona próxima. Revista del Instituto de Estudios en Educación, 11, pp. 12-31.

Lipski, J. M. (2005 [1996]). El español de América. Madrid: Cátedra.

López Morales, H. (2012). La lengua española en el mundo actual. Conferencia del Dr. H. López Morales en la ceremonia de recepción del Doctorado Honoris Causa que le otorgó la Universidad de Heidelberg, Alemania. Valencia: Editorial Aduana Vieja.

Luján Castro, J. (2002). "La enseñanza del español como lengua extranjera en Europa: Datos generales y propuestas para su mejora”. En El español en el mundo. Anuario del Instituto Cervantes 2002. Barcelona: Círculo de Lectores/Plaza \& Janes: https:/cvc.cervantes.es/lengua/anuario/anuario_02/ lujan/p01.htm (17-01-2018).

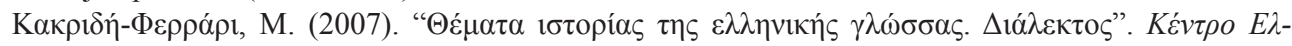
$\lambda \eta v \imath \kappa \eta ́ \varsigma \Gamma \lambda \omega \sigma \sigma \sigma \alpha \varsigma:$ http://www.greek-language.gr/greekLang/studies/history/thema_02/index.html [Kakride-Ferrari, M. (2007). "Temas de historia de la lengua griega. Dialecto". Centro de la Lengua Griega:

http://www.greek-language.gr/greekLang/studies/history/thema_02/index.html] (20-04-2019).

Makri, V. (2015). ¡Dificultades fonéticas de los chipriotas que aprenden español como lengua extranjera". En Actas de las VII Jornadas de Formación para Profesores de Español en Chipre, Nicosia: Centro de Lenguas-Universidad de Chipre.

Martinet, A. (1936). "Neutralisation et archiphonème", Travaux du Cercle Linguistique de Prague, 6, pp. 46-57.

Martinet, A. (1968). Elementos de la lingüistica general. Madrid: Gredos.

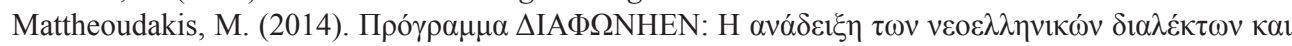

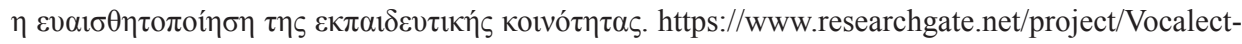
vowels-of-Greek-dialects. [Mattheoudakis, M. (2014). Programa VOCALECT: Apreciación de

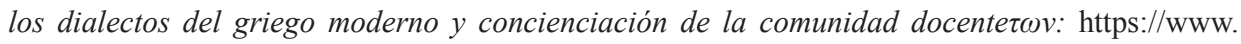
researchgate.net/project/Vocalect-vowels-of-Greek-dialects] (18-04-2019).

McCurdy, R. R. (1975). "Los isleños de la Luisiana. Supervivencia de la lengua y folklore canarios", Anuarios de Estudios Atlánticos, 21, pp. 471-591.

Montes Giraldo, J. J. (1962). "Sobre el habla de San Basilio de Palenque (Bolívar, Colombia)", Thesaurus, Boletín del Instituto Caro y Cuervo, 17(2), pp. 446-450.

Moreno, F. (1988). "Despalatalización de ñ en español”, Lingüística Española Actual, X, pp. 61-72.

Moreno, F. (1996). “Castilla La Nueva”. En Alvar, M. (dir). Manual de dialectología hispánica. El español de España. Barcelona: Ed. Ariel, pp. 213-232.

Moreno, F. (2010). Las variedades de la lengua española y su enseñanza. Madrid: Arco/Libros.

Moreno, F. y Otero, J. (2008). Atlas de la lengua española en el mundo. Barcelona: Editorial Ariel, S.A. 


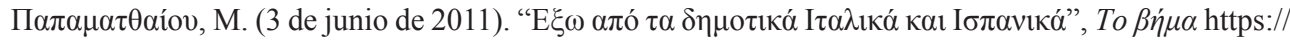
www.tovima.gr/2011/06/03/society/eksw-apo-ta-dimotika-italika-kai-ispanika/ [Papamatthaiou, M. (3 de junio de 2011). "El italiano y el español se quedan fuera de las escuelas", To $\beta \eta \mu \alpha$ https:// www.tovima.gr/2011/06/03/society/eksw-apo-ta-dimotika-italika-kai-ispanika/] (24/4/2019).

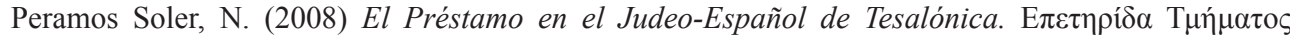

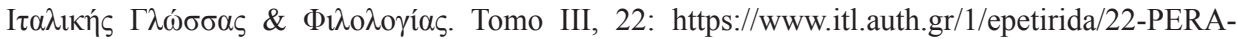
MOS\%20SOLER.pdf (23/04/2019).

Quesada Pacheco, M. Á. (2000). El español de América. Cartago: Editorial Tecnológica de Costa Rica. Quilis, A. (1995). "Notas de fonética del español de Nicaragua". En Martín Zorraquino, M. A. y T. Blesa (coords.). Homenaje a Félix Monge: estudios de lingüística hispánica. Madrid: Gredos. pp. 379-386.

Quilis, A. (1999 [1993]). Tratado de fonología y fonética españolas. Madrid: Gredos. Segunda edición. Quilis, A. y C. Casado Fresnillo (1995). La lengua española en Guinea Ecuatorial. Madrid: UNED. Quilis, A. y C. Casado Fresnillo (2008). La lengua española en Filipinas. Madrid: CSIC.

Quilis, A. y M. J. Quilis Sanz (2003). "Datos para la caracterización fonética del español de Bolivia". En Moreno, F., J. A. Samper, M. Vaquero, M. ${ }^{a}$ L. Gutiérrez, C. Hernández, F. Gimeno-Menéndez (coord.). Lengua, variación y contexto. Estudios dedicados a Humberto López Morales, II. Madrid: Arco Libros, pp. 775-791.

Real Academia Española y Asociación de Academias de la Lengua (2011). Nueva gramática de la lengua española. Fonética y Fonología. Madrid: Espasa Libros, S. L.

Richards, J, C., J. Platt, y H. Platt (1997). Diccionario de Lingüística Aplicada y enseñanza de lenguas. Barcelona: Ariel.

Rodríguez Lifante, A. (2010). "Español como Lengua Extranjera en Grecia: su aprendizaje en la enseñanza media reglada", RedELE: https://www.mecd.gob.es/educacion/mc/redele/biblioteca-virtual/ numerosanteriores/2011/memoriamaster/1-trimestre/albertorodriguez.html (17-01-2018).

Rodríguez Lifante, A. (2015). Motivación y actitudes como variables afectivas en aprendices griegos de español como lengua extranjera (tesis doctoral). Alicante: Universidad de Alicante.

Rodríguez-Lifante, A. (2015). La enseñanza del español como lengua extranjera a aprendices griegos: evolución, situación y perspectivas del aprendizaje e investigación sobre ELE en Grecia. Madrid: Ediciones del Orto.

Santos Gargallo, I. (1993). Análisis contrastivo, análisis de errores e interlengua en el marco de la lingüistica contrastiva. Madrid: Síntesis.

Subdirección General de Cooperación Internacional y Promoción Exterior Educativa (2018). El mundo estudia español. Madrid: Secretaría General Técnica. Centro de Publicaciones. Ministerio de Educación y Formación Profesional: https://sede.educacion.gob.es/publiventa/descarga.action?f_ codigo_agc=19365 (06-03-2019).

Tarkki, P. (1995). El español en los campamentos de refugiados de la República Árabe Saharaui Democrática. Helsinki: Centro Iberoamericano de la Universidad de Helsinki.

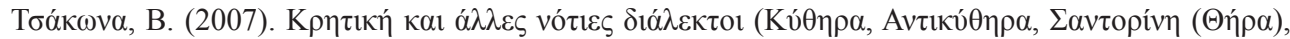

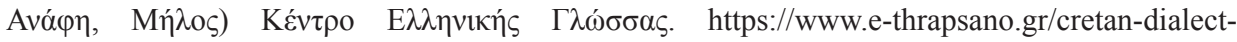
articles/278-cretan-dialect-and-other [Tsakona, B. (2007). El cretense y otros dialectos del sur (Citera, Anticitera, Santorini (Tera), Ánafe, Melos). Centro de la Lengua Griega. https://www.ethrapsano.gr/cretan-dialect-articles/278-cretan-dialect-and-other] (17-04-2019).

Trubetzkoy, N. S. (1949). Principes de phonologie. París: Klincksieck.

Weinreich, U. (1953). Languages in Contact: Findings and Problems. Nueva York: Publications of the Linguistic Circle of New York.

VV. AA. (2009). "Salónica, la capital sefardí de los Balcanes". En El legado de Sefarad. Centro Virtual Cervantes (CVC): https://cvc.cervantes.es/artes/sefarad/cartografia/salonica3.htm (15-04-2019). 